NBER WORKING PAPER SERIES

COMMERCIAL POLICY IN A PREDATORY WORLD

James E. Anderson

Working Paper 12576

http://www.nber.org/papers/w12576

\author{
NATIONAL BUREAU OF ECONOMIC RESEARCH \\ 1050 Massachusetts Avenue \\ Cambridge, MA 02138 \\ October 2006
}

\begin{abstract}
An earlier version of this paper was presented to the NBER ITI Summer Institute in July 2006. I am grateful to participants for helpful comments, especially Barbara Spencer. Earlier versions were also presented at Penn State University and the University of Missouri. The views expressed herein are those of the author(s) and do not necessarily reflect the views of the National Bureau of Economic Research.

(C) 2006 by James E. Anderson. All rights reserved. Short sections of text, not to exceed two paragraphs, may be quoted without explicit permission provided that full credit, including $\odot$ notice, is given to the source.
\end{abstract}


Commercial Policy in a Predatory World

James E. Anderson

NBER Working Paper No. 12576

October 2006, Revised June 2008

JEL No. F13,K42,O17

\begin{abstract}
Mutual causation of predation and trade induces novel effects of commercial policy in this paper. The model can explain trade volume responses to market widening initiatives that are otherwise puzzlingly 'too big' or 'too small'. Efficient commercial policy (broadly defined) depends crucially on the strength of enforcement. Externalities arising between traders are normally internalized by subsidizing (taxing) trade when enforcement is weak (strong). Efficient regional policy squeezes weak enforcement markets while subsidizing strong enforcement markets. Tolerance (intolerance) of smuggling is rational when enforcement is weak (strong).
\end{abstract}

James E. Anderson

Department of Economics

Boston College

Chestnut Hill, MA 02467

and NBER

james.anderson.1@bc.edu 
Commerce is subject to substantial predation. Officials demand bribes, port workers require payments off the books, petty theft is common, hijacking occurs in some locations. Africa provides spectacular examples. The Economist (Dec. 19, 2002) reports the story of a beer truck that loses $1 / 3$ of its load to extortionists at 47 roadblocks along 313 miles of road from Douala to Bertoua in Cameroon.

Moving from anecdote to data, Brunetti, Kisunko and Weder (1997) report survey evidence that corruption (official extortion) is ranked second only to taxation as an obstacle to business. Anderson and Marcouiller (2002) provide econometric evidence that insecurity reduces trade. For example they argue that insecurity is as destructive of trade to Latin American countries as are their protectionist trade policies.

While trade is reduced by predation, predation may also respond to trade. Mixed evidence on the success of trade liberalizations suggests two way causation between trade and (hidden) trade costs. ${ }^{1}$ Two way causation is also suggested by evidence that the quality of institutions has no simple relationship to income per capita. Anderson and Marcouiller (2002) report a composite security score for 48 countries in 1996, reproduced below as Table 2 from that paper. Italy ranks below India and Indonesia despite despite being much richer, while the US and Spain are far from the top despite their wealth.

Commercial policy in this paper is interpreted to include market widening or narrowing policies such as terms of access to and provision of infrastructure. ${ }^{2}$ Commercial policy has complex interactions with security in a world with predators. On the one hand, predation or the threat of predation may reduce or prevent trade expansion that would otherwise occur. On the other hand, liberalization may improve security as expanded trade draws erstwhile predators into legitimate activity. These forces suggest that trade gener-

\footnotetext{
${ }^{1}$ Some regional agreements such as NAFTA create much more intra-regional trade than standard models predict (Anderson and van Wincoop, 2002), while others produce disappointingly little. Schiff and Winters (2003, p. 32) review 9 episodes of developing country regional agreements, of which 2 decreased trade and 2 others increased trade very modestly. Schiff and Winters report more sophisticated evaluation of the effect of regional agreements, with much the same conclusions. The Central American Common Market (CACM) has a particularly interesting history. In its first form it increased trade spectacularly between 1960 and 1970, trade fell in the 70's following on the outbreak of civil war and the agreement eventually died. The reestablishment of the CACM in 1991 led to a modest increase in intra-regional trade.

${ }^{2}$ This definition was the common usage of the era of the classical economists.
} 
ates externalities. Efficient commercial policy in an insecure world should internalize the externality that flows between trade and security.

Traders and predators being legendarily footloose, commercial policy in one market is likely to generate an externality on other markets that is distinct from the usual terms of trade externality. Also, the security externality travels between legitimate markets and those for smuggled goods, suggesting that internalization may involve tolerance or intolerance for smuggling.

This paper develops a model of trade and commercial policy in a predatory world to address these questions. The model is based on Anderson and Bandiera (2006). The dramatis personae of the model are merchants, traders, and predators. ${ }^{3}$ Trade requires labor drawn from the same pool as predators. ${ }^{4}$ Merchants provide the capital required to carry on trade. They may form a guild that controls the volume of trade. ${ }^{5}$

The familiar language of international trade theory is used to describe commercial policy, but the model applies to regional policy as well, and the externalities acting between markets are likely to be more powerful for regions within countries. Commercial policy is modeled as taxes or subsidies to trade but should be interpreted as including terms of access to infrastructure.

Enforcement is taken as exogenous. Many aspects of enforcement are slow moving with respect to commercial policy and trade volume, so the setup has

\footnotetext{
${ }^{3}$ Like Tom Stoppard's Rosenkrantz and Guildenstern Are Dead, which moves the actions in Shakespeare's Hamlet offstage while the offstage action moves onstage, the action of standard trade theory moves offstage while the merchants, predators and traders move onstage. I am in debt to Avinash Dixit for elaborating this analogy.

${ }^{4}$ British seaports in the age of Napoleon provide an example. In historical fiction of Patrick O'Brian, the port towns of the southwest coast of England provided labor markets for sailors who could choose to work on legitimate commercial ships, privateers (who sometimes preyed on British ships as well as their legitimate French prey), or smugglers. Internationally, such sailors could locate in pirate ports of the Caribbean from any original home port. Ship's crews in long distance trade were commonly quite heterogeneous in nationality. Legendarily meticulous in his research, O'Brian reportedly was consulted as an authority by professional historians of the period.

Modern ports similarly provide a venue for trade services workers who can also act as predators, stealing cargo or imposing delays on shippers unless bribes are paid to expedite the movement of goods.

${ }^{5}$ There is some evidence that monopoly power may be important in trade services. US agricultural trade is dominated by a monopolist while much trade in manufactures is carried on by distributers owned by or closely tied to monopolistically competitive firms. Anderson and van Wincoop (2004) note that apparent markups vary inversely with elasticities of substitution, consistent with monopoly power.
} 
a short run rationale and permits a clear focus on the many interesting issues of commercial policy in a predatory world. For treatment of enforcement that is endogenous to commercial policy and trade volume, see Anderson (2008). The qualitative features of this paper remain valid.

Section 1 sets out the analysis. Competitive merchants impose two externalities on each other. A positive externality, safety in numbers, arises because a marginal expansion of trade raises the success rate of shipment for all merchants. A negative externality arises because trade expansion raises the merchants' cost of hiring workers. The net effect of these externalities is positive when enforcement is weak and negative when enforcement is strong. The model identifies strong and weak enforcement regimes parametrically. Then the setup expands to a second market connected to the first because both draw labor and predators from a common pool. This gives rise to externalities across markets, described here as international for access to the familiar tools of international trade theory.

Section 2 analyzes the comparative statics of commercial policy. Trade volume on the intensive margin responds to liberalization by more, the weaker is enforcement. On the extensive margin, in contrast, liberalization is more likely to initiate trade the stronger is enforcement. Thus the model can explain episodes where liberalization increases trade by 'too much' or 'too little' compared to standard policy model predictions.

Efficient commercial policy is analyzed in Section 3. The sign of efficient policy depends crucially on the strength of enforcement. A merchant interest government in an isolated market that internalizes the externalities of competitive trade should subsidize trade when enforcement is weak and tax trade when enforcement is strong. A trading monopoly will internalize the externalities; no role for policy arises. ${ }^{6}$

International externalities create a role for commercial policy regardless of market structure locally. Nash playing merchant interest governments typically should subsidize trade. When enforcement is strong, subsidization arises because profit-shifting is served by raising rivals' costs through the labor market by subsidizing the national trading firm's expansion. When enforcement is weak and trade volumes are strategic complements, profit shifting is served by a subsidy because the subsidy induces foreign expansion

\footnotetext{
${ }^{6}$ One important reason for the formation of trading guilds was enforcement, but it is possible and historically accurate to think of competition in trade volume while cooperating for enforcement purposes.
} 
that improves security. In contrast, when enforcement is weak but trade volumes are strategic substitutes, Nash policies tax trade. The reason is that the tax induces a foreign expansion that improves security by enough to raise the sum of revenue and home profits. The model identifies the strategic interaction regimes parametrically.

Cooperative trade policies should always subsidize trade when enforcement is weak and always tax trade when enforcement is strong. The intuition is essentially the same as the competitive single market case - the two trading firms fail to internalize the externalities they generate properly. In contrast, when enforcement is weak in one region and strong in the other, the cooperative policy taxes trade in the weak enforcement region and subsidizes trade in the strong enforcement region, concentrating activity where enforcement is strong. This result suggests a tradeoff between efficiency and equity in regional development policies.

Section 4 considers trade policy toward parallel legal and illegal markets. Smugglers evade taxes but draw off predators from legal trade. The analysis shows that official tolerance of illegal markets alongside legal markets is beneficial when enforcement is weak and detrimental when enforcement is strong. An example of each is provided by early American history. Prior to 1763, in the age of Caribbean piracy, British policy was legendarily tolerant of smuggling. After 1763 the British Navy eradicated Caribbean piracy and British policy switched to intolerance of piracy. The model thus provides an economic rationale for the dramatic and consequential shift in British policy.

The basic logic of commercial policy in Sections 2-4 is derived for simplicity in a partial equilibrium setting in which traders arbitrage between fixed buyer and seller prices. The Appendix shows that the qualitative logic holds up in a general equilibrium model trade model. Monopoly power in this setting expands to internalize the effect of volume expansion on the buyers' willingness to pay.

Section 5 concludes with a discussion of desirable extensions.

The model is related to a literature on institutions and insecurity (for example, Dixit, 2004, and references therein) and a smaller literature on trade and insecurity (for example, Skaperdas and Syropoulos, 2001, 2002). The novelty of the present line of research is that, very plausibly, predation occurs on the trade activity itself. Anderson and Marcouiller (2005) investigate the existence of insecure trading equilibrium in a two country two good Ricardian general equilibrium trade model with fixed trade costs. Much of the commercial policy analysis of the paper fits into the strategic trade policy 
literature pioneered by Brander and Spencer (1985). It differs from that literature in that the sources of market interdependence are due to insecurity and internationally linked labor markets.

\section{Merchants, Traders and Predators}

Trade is carried on by trading firms who obtain goods from a low cost origin at fixed price $c$ and sell them in a high value destination at fixed price $b$, $b>c$. Trade costs are modeled with a neoclassical cost function, the result of cost minimizing choices of capital and labor subject to a Cobb-Douglas technology. Trade capital is in fixed supply for the trade services market. The cost function represents an industry of trading firms, each controlled by a merchant supplying capital and his own labor to the trade activity and hiring additional traders who are paid a market wage $w .^{7}$

The traders come from a labor pool of fixed size in which their alternative activity is preying on the trade. In equilibrium the predators must earn an expected return equal to their trade services wage $w$.

The traders and the predators interact in anonymous hide and seek. The objective probability of an encounter is assumed to be a logistic function of the ratio of predators to prey. Predators win all encounters if not prevented by the enforcement technology. Enforcement effort frustrates a portion of the encounters between predators and prey.

The 'win' by the predators can be theft of all the shipment, but more generally the win is a bargained share of the goods, encompassing extortion. Extortion is a more plausible interpretation in many circumstances, such as extortion by customs officials or the soldiers stopping the Cameroonian beer truck in the Economist story.

The basic elements of the model are the traders and predators and their technologies for these two alternative activities. Their general equilibrium interaction combines equality of returns in the two activities, the rational expectations equilibrium shipment success rate, the labor market clearing condition and the zero arbitrage (or profit maximizing) condition in trading. For simplicity, but inessentially, other channels of general equilibrium are shut down except in the Appendix. Traders and predators are not directly

\footnotetext{
${ }^{7}$ For simplicity, heterogeneity of merchants is assumed away, so they will all earn the same return on their capital. Or, if they differ in ability, there is a rental market to ensure that capital goes to its most productive use.
} 
involved either in production or consumption; their sole interest is the highest expected return on their time.

The merchants may be organized in a guild that colludes to control trade volume or they may freely compete. The competitive case is a useful benchmark because it reveals an externality that monopoly guilds can internalize, but that re-emerges when national guilds compete in a world market for trading services.

\subsection{Basic Elements}

\section{Traders}

Trade costs are given by the Cobb-Douglas cost function $w^{\alpha} r^{1-\alpha} q$ where $q$ is the trade volume, $w$ is the wage rate, $r$ is the service price of trade capital and $\alpha$ is the parametric cost share for labor. ${ }^{8}$ The trade services unit cost, equal to the marginal cost of a price-taking competitive trading firm, is given by: ${ }^{9}$

$$
t(q, w)=k w q^{(1 / \alpha-1)}, k>0 .
$$

The demand for labor in trade services is equal to ${ }^{10}$

$$
q^{1 / \alpha} k
$$

The buyers' willingness to pay is fixed at $b$ while any quantity of the good can be purchased by traders at fixed price $c, 0<c<b$. The gross arbitrage margin $b-c$ gives an incentive for merchants to enter trade by buying goods at $c$, incurring trade costs $t$ and hoping to sell at $b \geq c+t$.

\section{Predators}

Temporarily think of predation as robbery. The extension to extortion will be made subsequently. Predation is the alternative use of labor. Like traders, predators are risk neutral. ${ }^{11}$ A simple model of interaction between

\footnotetext{
${ }^{8} \mathrm{~A}$ number of the results hold for more general cost functions as will be noted below where applicable.

${ }^{9}$ The short run cost function with fixed capital $K$ is given by $k w q^{1 / \alpha}$, where $k=$ $[(1-\alpha) / K]^{(1-\alpha) / \alpha}>0$. This is formed by using $(1-\alpha) w^{\alpha} r^{-\alpha} q=K$ to solve for $r(w, K, q)$, then substituting to obtain $\bar{C}(w, K, q)=k w q^{1 / \alpha}$.

${ }^{10}$ Here we use Shephard's Lemma.

${ }^{11}$ Risk aversion in the absence of insurance markets would tend to diminish predation relative to trading under the plausible hypothesis that informal insurance and self insurance are easier for traders.
} 
traders and predators yields clear implications that should hold up more generally. Predators attempt to steal (eventually extort) goods while these are in transit between the two regions. Once the trader and buyer meet exchange is secure. ${ }^{12}$ Predators sell their loot in a thieves market at a price normalized to one. ${ }^{13}$

Traders and predators are specialized: traders never attack each other because such conflict is too expensive in the even match that results, and predators similarly do not attack each other even when one predator has goods to steal. Thus the only matches with economic significance are between traders and predators, and predators always win. There is at most one match per period. Traders cannot coordinate on a common defense strategy, though each trader can individually take defensive actions to avoid meeting the predators while in transit. Predators similarly do not coordinate offensive strategies.

The objective probability of successful shipment by traders is built as a compound of two elements, the avoidance probability and the enforcement probability. The probability that the prey avoids the predator is a decreasing function $F$ of the ratio of predators to prey, $B / q$, where the volume of trade is $q$ and the number of predators is $B$ (for bandits or bad guys). The objective avoidance probability is given by the logistic function $F(B / q)=1 /[1+$ $\theta B / q$ ] where $\theta$ is a parameter capturing the effectiveness of the predators' technology for seeking and chasing relative to the traders' ability to hide and run. The other element of shipment success is the enforcement probability $M$. Of those shipments which fail to avoid the predators, a fraction $M$ will succeed anyway. Thus the objective success rate is given by $F+(1-F) M=$ $M+(1-M) F$.

Predation is now readily interpreted as extortion. The $M$ parameter can represent a bargained share left to the trader following an encounter. Behind

\footnotetext{
${ }^{12}$ If both goods and money are subject to predation or if goods can be stolen or extorted from buyers after purchase, the setups are more cumbersome, but nothing essential changes. Moreover, it is quite plausible that goods in transit are less secure than goods at rest; our model focuses on a convenient limit case. Our simplifying assumption can be rationalized by enforcement at points of sale, by reputation of buyer and seller, or by the ability of massed concentrations of buyers and sellers to coordinate to deter opportunism which is against their collective interest.

${ }^{13}$ That traders and predators sell the goods at different prices reflects the intuition that consumers' willingness to pay for stolen or shady goods is different. All results are qualitatively unchanged if we assume that both traders and predators sell at the same price $b$.
} 
the bargaining outcome lie outside options which might reflect spoliation of the goods in the event of a struggle, or the effects of an alarm to the enforcers.

\section{Toward Equilibrium}

Agents form beliefs $\pi$ about the success rate of traders, and in equilibrium the beliefs converge on $M+(1-M) F$. The full equilibrium is solved for the values of $B$ and $q$, the wage rate $w$ and the equilibrium success rate $\pi$.

It is useful to first characterize the rational expectations success rate conditional on trade volume. Potential predators allocate themselves between predation and trading to equalize payoffs given the wage rate and their beliefs about success rates in predation. In equilibrium the beliefs converge to objective success rates (which depend on $B$ ). Labor market equilibrium links the wage to a given volume of trade, hence links the equilibrium success rate to a given volume of trade. The full equilibrium is solved from the zero profit condition in trading, embedding equilibrium wages and success rates.

\subsection{The Equilibrium Success Rate}

The agents' beliefs about $\pi$ determine the expected payoffs to trading and predation and hence the choice between the two activities. In rational expectations equilibrium, the subjective probability must equal the objective probability, the returns to labor on both types of activity must be equal and the labor market must clear.

The expected return to predation per predator is $(1-\pi) q / B,{ }^{14}$ while employment in trade services pays $w$. Agents are indifferent between predation and trade services when

$$
w=\frac{(1-\pi) q}{B} \Rightarrow \frac{B}{q}=\frac{1-\pi}{w} .
$$

Substituting the labor allocation condition (2) into the objective probability function yields the success rate conditional on the wage. For the logistic function this simplifies to: ${ }^{15}$

$$
\pi(w)=M+w / \theta .
$$

\footnotetext{
${ }^{14}$ Predators sell their loot securely in a thieves market at constant price normalized to one, without loss of generality.

${ }^{15}$ In general, the fixed point problem has a trivial solution at $\pi=1$, since $F(0)=1$. Graphing $F[(1-\pi) / w]$ against $\pi$ shows that if $\pi=1$ is the only solution, it is stable under the plausible hypothesis that the subjective probability $\pi$ adjusts toward the objective probability given the beliefs $F[(1-\pi) / w]$. If an interior solution exists and is unique, it must be stable because $-F^{\prime} / w<1$ in the neighborhood of the solution. In this case the
} 
The labor market clears when the total supply of labor $N$ is equal to the sum of labor demanded in trade services and predation. Using (2), (4) and the demand for labor in the trade industry $q^{1 / \alpha} k$ yields:

$$
N=k q^{1 / \alpha}+q[1-\pi(w)] / w
$$

Solving (4) for the unique ${ }^{16}$ market clearing wage yields the equilibrium wage function:

$$
W(q) \equiv \frac{q(1-M)}{N-k q^{1 / \alpha}+q / \theta} .
$$

Note that $W_{q}>0$, the equilibrium wage is an increasing function of trade volume. Moreover, the wage function is inelastic at low $(w, q)$ and elastic at high $(w, q)$ with a unique critical value of $q$ for which it is unit elastic. See Figures 1-3 for an illustration of the behavior of $W /(1-M) \equiv \Omega(q)$.

Substituting (5) into (3) yields the equilibrium success rate as a function of the volume of trade $q$ and of the exogenous parameters $(M, N, k, \theta, \alpha)$ :

$$
\Pi(q)=\pi[W(q)]=M+\frac{1-M}{\theta\left(N / q-k q^{1 / \alpha-1}\right)+1} .
$$

Notice that the success rate is increasing in the volume of trade, an effect called 'safety in numbers' by Anderson and Bandiera (2006). Safety in numbers arises because of increasing opportunity cost of predators. At constant opportunity cost $w,(2)$ implies that the equilibrium $B / q$ is constant, driven by free entry of predators.

\subsection{The Full Equilibrium}

The equilibrium volume of competitive trade is determined by the no arbitrage condition of profit-maximizing traders in a free entry equilibrium. Traders expect to break even when $\pi b-c-t=0$. Their beliefs about $\pi$ must be consistent with the equilibrium probability of success. The wage rate which helps determine the trade cost $t$ and the success rate $\pi$ must be

secure equilibrium is unstable. There could be multiple interior equilibria, depending on the shape of the cumulative density function $F$. With multiple equilibria, unstable interior solutions are flanked by stable interior solutions.

${ }^{16}$ The right hand side of (4) is decreasing in $w$ and is unboundedly large at very low $w$, so a unique stable solution exists. 
consistent with labor market equilibrium for the volume of trade. The full equilibrium of the model is determined by goods and labor market clearance simultaneously, embedding the equilibrium probability of success as a function of the wage.

The competitive equilibrium quantity for a given wage uniquely satisfies

$$
Q(w, M) \equiv q:\left(M+\frac{w}{\theta}\right) b-c-w k q^{\left(\frac{1}{\alpha}-1\right)}=0 .
$$

(7) together with (4) determines the equilibrium wage and quantity.

It is convenient to analyze equilibrium by replacing the wage with the normalized wage $\omega \equiv w /(1-M)$. Then $\pi=\omega(1-M) / \theta+M$ and thus $\omega / \theta$ gives the avoidance success rate of shippers. The equilibrium pair $(\omega, q)$ is determined as follows. Divide both sides of equation (5) by $1-M$ to form:

$$
W(q, M) /(1-M) \equiv \Omega(q)=\frac{q}{N-k q^{1 / \alpha}+q / \theta}
$$

Replace $w$ in $(7)$ with $\omega(1-M)$. The labor market equilibrium condition and the zero arbitrage condition can now be plotted in $q, \omega$ space. Figure 1 illustrates. Equilibrium with insecure trade is found where $\omega \leq \theta$, or equivalently $w \leq \theta(1-M)$. The graphs of $(8)$ and ( 7$)$ are drawn as functions of $\omega$ in the region $\omega \leq \theta$ for the case where $M b-c<0 .{ }^{17}$

For some parameter ranges, $Q(\omega(1-M), M)$ will lie everywhere below $\Omega$ and autarky is the only equilibrium. For other parameter ranges, secure trade is the only equilibrium. See Anderson and Bandiera (2006) for more discussion. This paper concentrates on the case of insecure equilibrium at point E in Figure 1.

The alternative form of the choice of trade volume is monopoly. This form becomes natural in the context of the merchant guilds required to solve the collective action problem of law enforcement. The earnings of capital in trade services are given by

$$
S(q, w, M)=\int_{0}^{q}(\pi b-c-t) d q=\left[(M+w / \theta) b-c-\alpha w k q^{1 / \alpha-1}\right] q .
$$

Competitive trading implies $S_{q}=0$ while monopoly trading implies

$$
\begin{aligned}
S_{q}+S_{w} W_{q} & =0 \\
& =[\pi b-c-t]+[(\pi-M) b-\alpha t] W_{q} q / W
\end{aligned}
$$

\footnotetext{
${ }^{17}$ If the condition is violated, some trade will always occur even if an encounter with a predator is certain. Thus this plausible condition opens the door to predation destroying all trade.
} 
under the plausible assumption that the monopoly understands the dependence of both trade costs and the shipment success rate on the underlying labor market equilibrium. ${ }^{18}$ Monopoly equilibrium lies in one of two regions. The strong enforcement case

$$
M>[(1-\alpha) b+\alpha c] / b
$$

implies that $S_{q}>0, S_{w}<0$ while the weak enforcement case

$$
M<[(1-\alpha) b+\alpha c] / b
$$

implies that $S_{q}<0, S_{w}>0$. It is helpful for analyzing strategic interaction below to restate the enforcement regime condition as

$$
M b-c<(>)(1-\alpha)(b-c),
$$

with the interpretation that the effectively secure gross margin falls short of or exceeds capital's share of the gross margin. Figures 2 and 3 illustrate, again using the normalized wage $\omega$. Further analysis is in the Appendix. As with competitive trade, autarky or secure trade may be the only stable equilibria, depending on parameters. Autarky cannot be a stable equilibrium with strong enforcement.

The guild uses its knowledge of the externalities generated in the labor market in choosing the optimal trade volume. There is a negative pecuniary externality due to the cost push from more trade to higher demand for labor to higher trade costs $t$. Opposing this is a positive non-pecuniary externality, safety in numbers, due to the rise in wages pulling predators into trade and increasing security. The weak enforcement case means in equilibrium that $S_{q}=\pi b-c-t<0$, associated with $S_{w}>0$, where the safety in numbers externality dominates the cost push externality. The strong enforcement case implies, in contrast, that cost push dominates safety in numbers.

\subsection{The Two Country Model}

Two markets are connected through their trading activities. Formally, there is define a second market parallel to the first, with foreign variables denoted

\footnotetext{
${ }^{18}$ The sophistication of the monopolist is not crucial to the qualitative results. In an early version of this model (Anderson and Bandiera, 2003) we modeled a naive monopolist who took the wage as given, understood that trade cost depended on $q$ given $w$, and understood through the objective probability $F$ that increases in $q$ would raise $\pi$ for given predation $B$. The qualitative results were the same as in the present case.
} 
by *. A common labor pool supplies all predators and all labor in trade services. As in the one country model, a rise in the wage both raises trade costs and improves security, but the effect now has an inter-market or international externality. A useful alternative interpretation of the model sees the * market as a smuggling activity. Legal market commercial policy has effects on the smuggling activity that affect the optimal policy.

The total supply of labor is equal to $N$. Market clearance implies

$$
N=k q^{1 / \alpha}++k^{*}\left(q^{*}\right)^{1 / \alpha^{*}}+q[1-\pi(w)] / w+q^{*}\left[1-\pi^{*}(w)\right] / w .
$$

This implies a market clearing wage

$$
w=W\left(q, q^{*}\right)=\frac{q(1-M)+q^{*}\left(1-M^{*}\right)}{N-k q^{1 / \alpha}-k^{*}\left(q^{*}\right)^{1 / \alpha^{*}}+q / \theta+q^{*} / \theta^{*}} .
$$

The graphical analysis of full equilibrium with one country's trade based on Figures 1-3 readily generalizes to the two country model. The parallels to Figures 1-3 depict, for example, the foreign market volume conditional on a given home market volume. The cross effects between markets run through the equilibrium wage function. A rise in home market volume raises the wage associated with any given foreign volume $q^{*}$.

\section{Comparative Statics of Commercial Policy}

Commercial policy is modeled here as a change in $c$. This is natural when the policy instrument is the price of access to infrastructure such as port facilities. Subsidized access is indeed very common. A trade tax also can be thought of as acting on $c$ when predation is understood as extortion. ${ }^{19}$ If predation is extortion by customs officials, then auditing may well compel corrupt officials to correctly collect taxes while extracting added bribes from shippers in order to let the goods through in a timely manner.

First consider the response of trade in a single market to a change in $c$, the policy-inclusive cost of the goods to traders. When trade is initially positive, the effect on marginal surplus is given by $S_{q c}=-1$. The result, not

\footnotetext{
${ }^{19}$ The metaphor of theft, in contrast, suggests that liberalization should be modeled as a rise in $b$, with tariffs only being paid on the goods which escape predation. The technical analysis of this case is a bit more complex because $b$ enters multiplicatively with $\pi$. This difference is inessential for the qualitative results.
} 
surprisingly, is a rise in trade volume $q$ as $c$ falls for given $M$, as illustrated in Figure 1 by the equilibrium point E moving northeast along $\Omega(q)$. With monopoly too, equilibrium trade volume rises with a fall in $c$, illustrated in Figures 2 and 3 .

An important implication of the model is that trade is ordinarily more responsive to liberalization on the intensive margin the lower is enforcement capability. Specifically $d q / d c$ is smaller in absolute value the higher is $M$, all else held equal. The discussion is in the Appendix. Intuitively, the importance of the safety in numbers externality declines as enforcement capability rises.

In contrast, consider the effect of liberalization on the extensive margin. ${ }^{20}$ Potential predation can prohibit trade initially (see Anderson and Bandiera, 2006, for details). In Figure 1, autarky is the only stable competitive equilibrium for initial parameter values such that the $\Omega(q)$ function lies outside the $Q(\omega, M)$ function. In this case, a fall in $c$ moves the market closer to a jump from autarky to an interior solution such as $E$ on the diagram. All else equal, the larger is $M$, the more likely it is that a given reduction in $c$ will cause the inception of trade, provided that $M<1 / 2{ }^{21}$ Thus extensive margin competitive responses are larger the higher is enforcement quality, for $M<1 / 2$. In contrast, for $M>1 / 2$, decreases in $c$ are less likely to increase trade on the extensive margin the larger is $M$.

Reductions in $c$ can similarly initiate monopoly trade starting from a weak enforcement regime. The inception of trade necessarily occurs if the fall in $c$ is large enough to flip the enforcement regime from weak to strong. That is because interior monopoly equilibrium always exists with strong enforcement (see Anderson and Bandiera, 2006 for more discussion). The regime flip is more likely for a given sized fall in $c$ the larger is $M$, hence this type of extensive margin rise in monopoly trade is, like competitive trade, more likely the larger is $M$. For a fall in $c$ that does not flip the enforcement regime, the analysis is essentially the same as the competitive case: the inception of trade is more likely the larger is $M$ provided that $M<1 / 2$. For $[\alpha b+(1-\alpha c] / b>M>1 / 2$, decreases in $c$ are less likely to increase extensive margin trade the larger is $M$.

\footnotetext{
${ }^{20}$ Recent theoretical and empirical work emphasizes that extensive margin changes are a very important component of overall trade volume responses to liberalization and other exogenous shocks.

${ }^{21}$ The critical value of $\omega$ for which $S_{q}(0, \omega)=0$ is given by $(c / b-M) /(1-M)$. The critical value is decreasing in $M$ for $M<1 / 2$.
} 
Trade liberalization in one market also spills over to change the volume in un-liberalized markets. Using signs for the spillovers derived in Sections 3 and 4 , liberalization reduces (increases) trade on the intensive margin in unliberalized monopoly markets when enforcement is strong (weak). It increases trade in unliberalized competitive markets when $c-M b>0$. Spillovers acting on the extensive margin can initiate trade in competitive markets (the $\Omega$ function shifts to the right in Figure 1), and in monopoly markets with weak enforcement.

These and other comparative static effects of endogenous trade cost parameters on $d q / d c$ implied by the model provide a framework to analyze the highly disparate responses of trade to liberalization episodes across countries. The model implies that $d q / d c$ is smaller the smaller is $k$, which embodies the merchant capital, infrastructure or technology. The elasticity of import demand, the usual parameter that determines the response to liberalization, can be incorporated into the comparative statics of liberalization based on the general equilibrium extension of the model laid out in Section 5.

\section{Efficient Commercial Policy}

Suppose that the government sets policy to maximize the profits of merchants. This assumption is natural in the model since merchants are the only location specific agents.

Mercantilist policy often granted trade monopolies. Interpreted in light of the model, this policy overcame the free rider problem of private enforcement provision while also maximizing profits by bestowing on merchants the monopoly power over trade volume. It may have been efficient. Alternatively, government or a merchant guild provides private enforcement but leaves volume to be competitively determined. What is the efficient trade policy?

Trade expansion has two effects on trade costs: the pecuniary cost push externality drives up the transport cost $t$ while the non-pecuniary safety in numbers externality raises the success rate on trade $\pi$. The net effect of the externalities is negative (cost push dominates) in strong enforcement equilibrium and the net effect is positive (safety in numbers dominates) in weak enforcement equilibrium.

Competitive merchants fail to internalize the externality, but their merchant interest government can do so, subsidizing trade in weak enforcement 
equilibrium and taxing trade in strong enforcement equilibrium. A trading monopoly will in contrast internalize both externalities. In a multi-market setting, the trading monopoly fails to fully internalize, however, opening a role for government. When the markets are separated by borders, rival governments play Nash policies, or they may cooperate.

\subsection{Efficient Policy in a Single Market}

The net payoff for a government that acts in merchants' interest but also cares about revenue is given by

$$
G(c)=S[q(c), W[q(c)], c]+\lambda q\left(c-c^{0}\right) .
$$

$\lambda \geq 1$ is the Marginal Cost of Funds (MCF) that must be raised from alternative revenue sources. For simplicity $\lambda$ is assumed to be constant. $q\left(c-c^{0}\right)$ is the revenue raised by a $\operatorname{tax} c-c^{0}$ when this is positive or the subsidy required when $c-c^{0}$ is negative.

The government influences the choice of $q$ by altering $c$ with a tax or subsidy. Competitive traders determine a trade volume such that $S_{q}=0$ while a merchant guild sets aggregate volume such that $S_{q}+S_{w} W_{q}=0$.

For the monopoly trade case, using the monopolist's first order condition, the government objective function rises with $c$ according to

$$
\begin{aligned}
G_{c} & =(\lambda-1) q+\lambda\left(c-c^{0}\right) d q / d c=-q\left[1-\lambda / M C F^{c}\right] \\
M C F^{c} & \equiv\left[1+\frac{c-c^{0}}{c} \frac{c d q}{q d c}\right]^{-1} .
\end{aligned}
$$

If lump sum taxation is available, $\lambda=1$ and $G_{c}<0$ except at $c=c^{0}$, free trade, where $M C F^{c}=1$. Otherwise, $G_{c}=0$ provides a revenue motive to require $c>c^{0}$, at least a small amount of trade taxation to substitute for more expensive alternative revenue sources. ${ }^{22}$

In contrast, competitively determined trade implies an untreated externality at the free trade point.

$$
G_{c}=(\lambda-1) q+\lambda\left(c-c^{0}\right) d q / d c+S_{w} W_{q} d q / d c .
$$

\footnotetext{
${ }^{22}$ The second order condition for this and succeeding problems is normally met, as may be checked in this case: $G_{c c}=(2 \lambda-1) d q / d c+\lambda\left(c-c^{0}\right) d^{2} q / d c^{2}$, which is negative by $d q / d c<0$ unless the combination of large taxes and $d^{2} q / d c^{2}>0$ prevents it. In that case, a lower tax rate will satisfy both the first and second order conditions.
} 
Proposition 1 With no international externalities and no revenue motive $(\lambda=1)$, the optimal policy of the merchant interest government is: (a) laissez faire when the merchant guild has monopoly power in trade; (b) $c-c^{0}=$ $-S_{w} W_{q}$ in the absence of monopoly power; subsidize trade when enforcement is weak, $S_{w}>0$, and tax trade when enforcement is strong, $S_{w}<0$.

Proposition 1 provides a rationale for the Mercantilist predilection for trading monopolies in an era when predation was very strong. Revenue motives combine with the domestic externality correction when $\lambda>1$. This observation and Proposition 1 imply that when revenue is expensive and enforcement is weak, monopoly secures efficient trade while avoiding the subsidy needed for efficient competitive trade. State monopoly grants would have been more effective than merchant guilds that would have been vulnerable to defection and entry, with consequent loss of full internalization of the externality. ${ }^{23}$

\subsection{International Externalities}

In the two country model, a trade monopoly is assumed to operate exclusively in each market. International externalities travel through the common labor market. These international externalities operate independently of the standard terms-of-trade externalities that are shut down by assumption.

The two trade monopoly rivals lack the commitment power by which to exploit the effect of their decisions on their rival's choice of trade. Their governments can supply the lack with profit-shifting trade policies.

The Nash equilibrium trade policies will in most parameter ranges subsidize trade. This occurs for two separate reasons. When enforcement is mutually strong, profit shifting is served by raising rivals' costs through the labor market, achieved by subsidizing own trade. When enforcement is mutually weak and trade volumes are strategic complements, profits are raised by a subsidy that enduces foreign expansion because this improves the security of own trade. In contrast, when enforcement is mutually weak but trade volumes are strategic substitutes, a tax on trade improves security by raising the rival's trade volume, and this serves to increase the sum of profits and revenue.

The Nash policies are inefficient. Cooperative policies achieve efficiency

\footnotetext{
${ }^{23}$ The model abstracts from standard dead weight loss due to the monopolist's ability to benefit from the dependence of $b$ and/or $c$ on volume.
} 
by internalizing the international externality of policy. Cooperative policy subsidizes trade in mutual weak enforcement equilibrium and taxes trade in mutual strong enforcement equilibrium. When enforcement regimes differ, efficient cooperative policy subsidizes the strong and taxes the weak. Note again that the model's subsidy implications are not unrealistic since subsidy to trade realistically comes via infrastructure provision that lowers $c$ without full taxation to cover the provision.

Trade is determined by foreign and domestic guilds in a Nash equilibrium defined by

$$
\begin{aligned}
S_{q}+S_{w} W_{q} & =0 \\
S_{q^{*}}^{*}+S_{w}^{*} W_{q^{*}} & =0 .
\end{aligned}
$$

This system of equations yields the Nash equilibrium volumes $q\left(c, c^{*}\right), q^{*}\left(c, c^{*}\right)$.

For simplicity in modeling government objectives, assume $\lambda=1=\lambda^{*}$, so there is no revenue motive, and assume that trade is monopolistically determined so there is no domestic externality correction motive. The objective functions of the two governments are given by $G=S\left\{q\left(c, c^{*}\right), W\left[q\left(c, c^{*}\right), q^{*}\left(c, c^{*}\right)\right], c\right\}+$ $q\left(c-c^{0}\right)$ and $G^{*}=S^{*}\left\{q^{*}\left(c, c^{*}\right), W\left[q\left(c, c^{*}\right), q^{*}\left(c, c^{*}\right)\right], c^{*}\right\}+q^{*}\left(c^{*}-c^{* 0}\right)$.

\subsubsection{Nash Trade Policies}

Each government sets trade policy to maximize its objective function given the policy of the other government. The Nash equilibrium in noncooperative trade policies is determined by:

$$
\begin{aligned}
G_{c} & =0=\left(c-c^{0}\right) d q / d c+S_{w} W_{q^{*}} d q^{*} / d c \\
G_{c^{*}}^{*} & =0=\left(c^{*}-c^{* 0}\right) d q^{*} / d c^{*}+S_{w}^{*} W_{q} d q / d c^{*} .
\end{aligned}
$$

While the monopoly is able to internalize the effect of its own volume decision on the labor market, it is by assumption unable to do so for foreign volume. This leaves a role for government to respond at the margin to the international externality.

The tax or subsidy implied is

$$
c-c^{0}=-S_{w} W_{q^{*}} R_{q}^{*}
$$

where $R_{q}^{*}$ is the slope of the foreign best response function, the values of $q^{*}$ which satisfy $S_{q^{*}}^{*}+S_{w}^{*} W_{q^{*}}=0$ for any given value of $q$. A similar optimal 
tax characterizes the foreign government's policy. Since $W_{q^{*}}>0$, the sign of the tax is the sign of $-S_{w} R_{q}^{*}$. Formally,

Lemma 1 In Nash equilibrium, trade is taxed (subsidized) when $S_{w}$ and $R_{q}^{*}$ differ in (have the same) sign.

The slope of the best response functions is determined by differentiating the first order conditions of the trade guilds. Assuming the second order condition is met, the Appendix shows that the sign of $R_{q}^{*}$ is given by the sign of

$$
c-M^{*} b^{*}+\frac{S_{w}^{*} w}{q^{*}} \Omega_{q}^{*},
$$

where $\Omega^{*}=W_{q^{*}} q^{*} / W$ and $\Omega_{q}^{*}=\partial \Omega^{*} / \partial q$. The Appendix shows that $\Omega_{q}^{*}>0$. Recall that enforcement is strong, $S_{w}^{*}<0$, (weak, $\left.S_{w}^{*}>0\right)$ as $M^{*} b^{*}-c>(<$ )$(1-\alpha)\left(b^{*}-c\right)$. Entirely analogous conditions sign $R_{q^{*}}$.

Lemma $\mathbf{2}$ (a) Trade volumes are strategic substitutes if enforcement is strong, (b) trade volumes are strategic complements if enforcement is weak and $M^{*} b^{*}-c<0$, (c) trade volumes may be strategic substitutes if $0<$ $M^{*} b^{*}-c<(1-\alpha)\left(b^{*}-c\right)$.

The possibilities for non-cooperative trade policy equilibria are presented in Table 1. The equilibria represented by the first two rows and columns distinguish between two types of weak enforcement equilibria, those with strategic complementarity and those with strategic substitutability. The first two rows and columns represent equilibria with weak enforcement, which may not exist for all parameter values. The middle column represents the possible case where $R_{q}^{*}<0$ despite $S_{w}^{*}>0$. A necessary condition for the middle column case is $(1-\alpha)\left(b^{*}-c\right)>M^{*} b^{*}-c>0$.

One case of subsidy has a familiar cause, though in a new setting. When $S_{w}<0$ and $S_{w}^{*}<0$, strong enforcement equilibrium, trade volumes are strategic substitutes, $R_{q}^{*}<0$ and $R_{q^{*}}<0$. The rationale for subsidy is essentially the Brander-Spencer profit-shifting mechanism: subsidizing the home trader monopoly under strategic substitutability permits it to take more of the world's trade and hence profits from trade.

In contrast, weak enforcement equilibrium induces optimal subsidies through a different mechanism. In this case there is strategic complementarity. Due to 'demand complementarity', ${ }^{24}$ the home trader benefits from the foreign trader's expansion. Due to strategic complementarity, the home government

\footnotetext{
${ }^{24}$ Demand complementarity is used here to describe a positive response of the markets' willingness to pay for trade services, $\pi b-c-t$, to a rise in $q^{*}$.
} 
Table 1: Nash Equilibrium Policies

\begin{tabular}{c|ccc}
\hline & Weak, $R_{q}^{*}>0$ & Weak, $R_{q}^{*}<0$ & Strong \\
\hline Weak $^{*}, R_{q^{*}}>0$ & subsidy, subsidy* & subsidy, tax* & tax, tax* \\
Weak*,$R_{q^{*}}<0$ & tax, subsidy* & tax, tax* & subsidy, tax* \\
Strong* & tax, tax* & tax, subsidy* & subsidy, subsidy* \\
\hline
\end{tabular}

achieves internalization of this benefit through subsidy. Weak enforcement can also induce optimal taxes when trade volumes are strategic substitutes. In this case the security improving benefit of foreign expansion is obtained by taxing own trade.

Taxation also arises when $S_{w}$ and $S_{w}^{*}$ differ in sign. The intuitive rationale for this case as compared to the cases under (i) is similar to the switch in the Brander-Spencer logic made by Eaton and Grossman: with 'demand substitutes' in the home market $\left(S_{w}<0\right)$ but strategic complementarity $\left(S_{w}^{*}>0\right)$, taxation is the optimal rent-shifting policy. Taxation also arises in this model with 'demand complements' in the home market but strategic substitutability for the foreign response, a more novel possibility relative to the Brander-Spencer model literature. Brander (1995) surveys all the possibilities in an abstract setup that explores the four possible combinations of strategic substitutability/complementarity and demand substitutes/complements, an abstraction clothed here with the details of a model in which each possibility can easily be realized with appropriate combinations of the strength of enforcement in the two markets.

\subsubsection{Cooperative Trade Policies}

Now consider international cooperation in trade policy. The response of joint surplus to $c$ and $c^{*}$ is defined by

$$
\begin{aligned}
& G_{c}+G_{c}^{*} \\
& G_{c^{*}}+G_{c^{*}}^{*} .
\end{aligned}
$$

Here the new cross effects $G_{c}^{*}, G_{c^{*}}$ incorporate the effect of domestic policy on the other government's objective function. The implications for jointly desirable policy change are seen by evaluating the cross effect at the Nash equilibrium values of policy. Considering the home policy for example, at the Nash equilibrium policies, $G_{c}+G_{c}^{*}=S_{w}^{*} W_{q} d q / d c$. This has the sign of $-S_{w}^{*}$. 
The full jointly optimal trade policies are defined by

$$
-\left(c-c^{0}\right)=S_{w} W_{q^{*}} R_{q}^{*}+S_{w}^{*} W_{q}+\left(c^{*}-c^{* 0}\right) R_{q}^{*}
$$

and the analogous expression for the foreign policy. The solution is

$$
\begin{gathered}
c-c^{0}=\frac{-S_{w}^{*} W_{q}+S_{w}^{*} W_{q} R_{q}^{*} R_{q^{*}}}{1-R_{q}^{*} R_{q^{*}}}=-S_{w}^{*} W_{q} \\
c^{*}-c^{* 0}=\frac{R_{q}^{*} R_{q^{*}} S_{w} W_{q^{*}}-S_{w} W_{q^{*}}}{1-R_{q}^{*} R_{q^{*}}}=-S_{w} W_{q^{*}}
\end{gathered}
$$

Proposition 2 (a) When policies are set cooperatively, trade should be subsidized (taxed) in mutual weak (strong) enforcement equilibrium. (b) With enforcement asymmetry, the weak market should be taxed and the strong market should be subsidized.

The optimal interventions internalize the international externality of domestic trade policy. Proposition 2 (b) deals with the case where one country or region has weak enforcement and the other has strong enforcement. Strongly asymmetric regional policies are efficient - the weak are weakened and the strong are strengthened.

The need for intervention arises with cooperative policies because in contrast to the one country case, the two national guilds do not internalize the effect of their actions on each other. This discussion and the preceding discussion of the sign of optimal Nash policy suggests that the case for international coordination of trade policy is even stronger than the standard tariff case because the sign of the trade policy can switch in moving from noncooperative to cooperative equilibrium. The difference between the present analysis and the standard analysis of Nash vs. cooperative tariffs is wide. The present analysis centers on an international externality which operates through endogenous trade costs rather than endogenous terms of trade.

The preceding analysis applies to regional policy as well as international commercial policy. This application is more natural because coordination is far more natural when thinking of a national government constraining the actions of state governments and because the model is based on interaction through a common labor market. For example, in U.S. history before the Civil War, New York and Pennsylvania both competitively subsidized canal and rail building to the interior of the country while after the Civil War the rail subsidies were determined nationally. Asymmetric enforcement regimes 
cause a poignant conflict between efficiency and equity for national government policy toward regions. Efficiency indicates strengthening the strong and weakening the weak, but equity suggests acting in the opposite direction.

\section{Commercial Policy with Smuggling}

What does commercial policy look like in a predatory world that includes an illegal market such as a smuggled version of legal goods or another illegal good? The two market setup can be reinterpreted to reflect this common situation of parallel legal and illegal markets. The ${ }^{*}$ variables now refer to those of the illegal market. Policy includes taxes or subsidies in the legal market and tolerance or intolerance of the illegal activity.

Collective action being more difficult in illegal activity, trade volume in the illegal market is likely to be set competitively and 'enforcement' in the illegal market is exogenous with $0 \leq M^{*}<M . M^{*}$ can be greater than zero, reflecting extortion by predators from smugglers. (An alternative setup is explored in Anderson and Bandiera, 2006, in which a mafia provides enforcement in the illegal market and its monopoly pricing is a key element in the analysis of anti-drugs policies.)

The 'best response' function of the smugglers reflects competitive reactions, $N_{q^{*}}^{*}=S_{q^{*}}^{*}\left[q^{*}, W\left(q, q^{*}\right)\right]=0 . R_{q}^{*}=-N_{q^{*} q}^{*} / N_{q^{*} q^{*}}^{*}$ is signed by $S_{q^{*} w}^{*} w=$ $\left[\left(\pi^{*}-M^{*}\right) b^{*}-t^{*}\right]=c^{*}-M^{*} b^{*}>0$ ordinarily. ${ }^{25}$ Thus illegal trade is ordinarily a strategic complement of legal trade.

Now consider the effect of smuggling on the response of legal trade to trade liberalization. The Nash equilibrium trade volumes are determined by $N_{q}=S_{q}+S_{w} W_{q}=0$ and $N_{q^{*}}^{*}=S_{q^{*}}^{*}\left[q^{*}, W\left(q, q^{*}\right)\right]=0$. Differentiating the system with respect to $c$ and solving yields $d q / d c=1 /\left[N_{q q}+N_{q q^{*}} R_{q}^{*}\right]$. Thus

Proposition 3 smuggling lowers (raises) $|d q / d c|$ as $N_{q q^{*}}<(>) 0$; i.e., as enforcement is strong (weak).

Turning to the implication for optimal trade policy, the first order condition for the government yields:

$$
G_{c}=\left[\left(c-c_{0}\right)+S_{w} W_{q^{*}} R_{q}^{*}\right] d q / d c=0 .
$$

The first order condition implies that:

\footnotetext{
${ }^{25}$ This is a plausible condition. If it is violated, even when a trader is certain to encounter a predator, at least some trade will always occur. The condition implies weak enforcement.
} 
Proposition 4 Absent revenue motives, trade in the presence of smuggling should be taxed in strong enforcement equilibrium and subsidized in weak enforcement equilibrium.

Proposition 4 suggests that high tax/high smuggling equilibria are not efficient. Thus revenue needs that require trade taxes in weak enforcement environments lay a heavy burden on the economy.

Anti- or pro-smuggling policy is another important policy instrument. Suppose the state can change $c^{*}$ by some costless action, such as permitting or denying smugglers access to port facilities. A fall in $q^{*}$ raises or lowers legal merchants' profits as enforcement is strong or weak. Formalizing this insight,

$$
G_{c^{*}}=\left[\left(c-c_{0}\right) R_{q^{*}}+S_{w} W_{q^{*}}\right] d q^{*} / d c^{*}=0 .
$$

When $c=c_{0}$, the optimal policy on $c^{*}$ drives $S_{w}=0$, assuming this is feasible with interior equilibrium. For $c-c_{0} \neq 0$, the optimal $c^{*}$ policy solves $S_{w}=-\left(c-c_{0}\right) R_{q^{*}} / W_{q^{*}}$. At the optimal $c$ policy, changes in $c^{*}$ are ordinarily effective in raising surplus further since the standard stability condition implies that $R_{q^{*}}^{*}>R_{q^{*}}$. For weak enforcement, $c<c_{0}$ and an interior optimum $c, c^{*}$ policy is possible where smuggling is subsidized optimally. For strong enforcement, $c>c_{0}$ and the optimal policy is to attack smuggling to the extent possible; no interior optimum is possible. The implication is that $c^{*}$ policy is more powerful than $c$ policy. The global analysis makes this point clear, as given in Figure 4 for the case where enforcement is weak and Figure 5 for the case of strong enforcement.

The government's policy in the merchants' interests in effect confers on the trade monopoly a first mover advantage that it lacks in setting its trade strategy. When the government is able to affect the smugglers' cost directly, it can shift the smugglers' best response function along the legal market monopoly's best response function. Assume for the moment that such shifts are feasible while the interior insecure equilibrium still obtains. Then the optimal policy shifts the smugglers' reaction function to the optimal point where a legal market iso-profit contour is tangent to the legal market best response function, point $L^{*}$ on Figure 4 . This yields higher profits than those associated with the optimal $c$ given by point $L$ on Figure 4 . The analogous analysis for the case of strong enforcement is given in Figure 5.

Summarizing the implications:

Proposition 5 (a) The optimal smuggling policy of a revenue motivated government encourages it when enforcement is weak and suppresses it when 
enforcement is strong.

The analysis illuminates a crucial regime change in British policy toward its American colonies around 1763, the end of the Seven Years War (called the French and Indian War in its North American aspect). Official toleration of smuggling prevailed for a century prior to 1763 as smugglers almost openly used the major American ports. Afterwards, British intolerance of smuggling fueled resentment leading to the American Revolution.

Applying the model, weak enforcement prevailed prior to 1763 as British naval forces contended with their European rivals, especially the French in the 18th century. In terms of the model, $S_{w}>0$, hence rational tolerance was the optimal British policy. After 1763, the released British naval forces suppressed piracy in its Caribbean bases. By implication the equilibrium shifted to a strong enforcement regime where $S_{w}<0$ and intolerance of smuggling became rational for a government in the legal merchants' interest. ${ }^{26}$

In contrast, the usual economic explanation for the regime change of 1763 is the increased demand for revenue by the British government following its expensive war with the French. ${ }^{27}$ In terms of the model, however, an increased appetite for revenue cannot cause a rational regime change from tolerance to intolerance of smuggling. Formally, a rise in $\lambda$, the marginal cost of funds from alternative sources, normally leads to a rise in the tax on legal trade $c$. The effect of the rise in $\lambda$ and $c$ on smuggling policy is implied by

$$
G_{c^{*}}=\left[\lambda\left(c-c_{0}\right) R_{q^{*}}+S_{w} W_{q^{*}}\right] d q^{*} / d c^{*} .
$$

When enforcement is weak, the incentive to subsidize smuggling is increased, $G_{c}^{*}$ falls, while when enforcement is strong the incentive to attack smuggling is increased, $G_{c}^{*}$ rises.

${ }^{26}$ The model offers a novel economic interest explanation of the bitter divisions within the colonies during the Revolution: the switch to intolerance benefitted legal merchants while harming the merchant capital tied up in the illegal market, along with harming the common sailors. Loyalists have been estimated to comprise as much as $1 / 3$ of the population during the Revolution. In contrast, prior to 1763 the British policy of 'benign and salutary neglect' aided all three groups.

${ }^{27}$ The increased revenue demand story is somewhat problematic because the revenue motive operated during and prior to the war years too, when Americans under threat from the French and their native allies had a strong incentive to cooperate with the British in raising revenue for their defense, as indeed they did with funding colonial militias. Another problem with the revenue demand story is the relatively small revenues involved in actual British tax plans. The economic motive of this paper complements a plausible non-economic story offered by historians. After 1763 there was a shift to centralized and rational bureaucratic administration throughout the British Empire. 
A limitation of the model is that the exogeneity of $b$ shuts down a possible motive for anti-smuggling policy which could raise the willingness to pay for legal goods. However, this motive would also have operated before 1763, so it cannot explain the regime shift.

\section{Conclusion}

This paper provides a formal model of trade policy in a predatory world. Efficient trade policy in this world may often require subsidy to trade, realistically provided through subsidy to transport infrastructure. International externalities due to both cost push and non-pecuniary spillovers on the security of trade indicate the desirability of cooperation in setting trade policies. The model provides insights into why illegal markets operating alongside legal ones are sometimes tolerated and sometimes attacked.

A richer model of government would allow a deeper exploration of the interaction of trade liberalization with policies designed to affect the other costs of trade, especially those associated with enforcement costs. The merchant interest model has at least opened the door. Optimal commercial policy in this setup reveals key elements that will be at work in richer models.

A major challenge is to embed the government in political economy. One use of such a model would view the predators as corrupt customs officials with the costly enforcement being lobbying by merchants to reduce extortion by officials. The current model assumes a fixed cost of enforcement. It is simple to endogenize enforcement effort by allowing for a variable component, though it is not clear that it can stand as a good metaphor for lobbying costs to persuade a top politician to crack down on his corrupt bureaucracy. ${ }^{28}$

Another political economy challenge is the state's objective function. Usually the merchants' interest will be well represented in the state's objective function, but not fully, as here. States care about the interests of their legitimate citizens and even their illegitimate ones. Pointing the way forward, while in the current setup labor supplies both markets, the general equilibrium setup of Section 5 gives labor a locational identity in consumption.

The organization of the provision of enforcement is the another important topic for deeper exploration. Private enforcement is provided here by a trading monopoly or by a guild which permits competitive trading. It could

\footnotetext{
${ }^{28} \mathrm{I}$ am in debt to Avinash Dixit for pointing this out.
} 
alternatively be provided by a monopoly enforcer such as a mafia (see Anderson and Bandiera, 2006). Details of the economic environment are likely to determine which organizational form can be successful, and therefore which state policies may be able to reap the benefits of private enforcement without the costs of monopoly. Some types of enforcement activity are less purely public than the setup of this paper. Such forms are less subject to underprovision due to free riding, but may present negative externality problems (car alarms deflect predators onto unprotected cars). If the state takes over the provision of enforcement, it must of course collect revenues to pay for it. These may include revenue raised from the taxation of trade, leading to the interaction of trade taxes with the insecurity of trade.

Another useful extension of the present setup is to explore the effect of capital mobility on the merchants' interests, and hence the desirability of integration in the form of international capital mobility. 


\section{References}

Anderson, James E. (2008), "Economic Integration and the Civilizing Commerce Hypothesis", World Economy, 31, 141-57.

Anderson, James E. and Oriana Bandiera (2006), "Traders, Cops, and Robbers", Journal of International Economics, 70(1), 197-215; revised version of NBER Working Paper No. 9572.

Anderson, James E. and Douglas Marcouiller (2002), "Insecurity and the pattern of trade: an empirical investigation", Review of Economics and Statistics, 84, 345-52.

Anderson, James E. and Douglas Marcouiller (2005), "Anarchy and Autarky: Endogenous Predation as a Barrier to Trade", International Economic Review, 46, 189-214.

Anderson, James E. and Eric van Wincoop (2002), "Borders, trade, and welfare" in Brookings Trade Policy Forum 2001, Rodrik, Dani and Susan Collins, eds., Washington: The Brookings Institution.

Anderson, James E. and Eric van Wincoop (2004), "Trade Costs", Journal of Economic Literature, 42, 691-751.

Brander, James and Barbara Spencer (1985), "Export Subsidies and International Market Share Rivalry". Journal of International Economics,18-1, 83-100.

Brander, James (1995) "Strategic Trade Policy" in Gene Grossman and Kenneth Rogoff, eds. Handbook of International Economics, Vol. 3, NorthHolland.

Brunetti, Aymo, Gregory Kisunko and Beatrice Weder (1997), "Institutional Obstacles to Doing Business: Region-by-region Results from a Worldwide Survey of the Private Sector", World Bank Policy Research Paper No. 1759 .

Dixit, Avinash K. (2004), Lawlessness and Economics: Alternative Modes of Economic Governance, Princeton: Princeton University Press.

Smith, Adam (1976), The Wealth of Nations, Chicago: University of Chicago Press.

Schiff, Maurice and L. Alan Winters (2003), Regional Integration and Development, Washington: The World Bank.

Skaperdas, Stergios and Constantinos Syropoulos (2001), "Guns, Butter, and Openness: On the Relationship Between Security and Trade, American Economic Review, Papers and Proceedings, 91(2), 353-357. 
Skaperdas, Stergios and Constantinos Syropoulos (2002), "Insecure Property and the Efficiency of Exchange," Economic Journal, 112, 133-146. 


\section{Appendix 1: Strategic Cross Effects}

$R_{q}^{*}$ is obtained from totally differentiating the first order condition of the foreign trading duopolist $S_{q^{*}}^{*}+S_{w}^{*} W_{q^{*}}=0$ and solving for $d q^{*} / d q$. Analogous procedures apply to deriving $R_{q^{*}}$.

It simplifies the derivation to rewrite the first order condition as

$$
\left(\pi^{*} b^{*}-c-t^{*}\right)+\left[\left(\pi^{*}-M^{*}\right) b^{*}-\alpha t^{*}\right] \Omega^{*}=0
$$

where $\Omega^{*} \equiv W_{q^{*}} q^{*} / W$ and $\left[\left(\pi^{*}-M^{*}\right) b^{*}-\alpha t^{*}\right]=S_{w}^{*} w / q^{*}$. The $\operatorname{sign}$ of $R_{q}^{*}$ is given by the sign of the derivative of the first order condition with respect to $q$. Differentiate the left hand side of (16) with respect to $q$, yielding

$\left[\left(\pi^{*}-M^{*}\right) b^{*}-t^{*}\right] W_{q} / W+\left[\left(\pi^{*}-M^{*}\right) b^{*}-\alpha t^{*}\right] \Omega^{*} W_{q} / W+\left[\left(\pi^{*}-M^{*}\right) b^{*}-\alpha t^{*}\right] \Omega_{q}^{*}$.

Utilizing $\left[\left(\pi^{*}-M^{*}\right) b^{*}-\alpha t^{*}\right]=S_{w}^{*} w / q^{*}$, the preceding expression becomes

$$
-(1-\alpha) t^{*} W_{q} / W+\frac{S_{w}^{*}}{q^{*}} W_{q}\left(1+\Omega^{*}+\Omega_{q}^{*} q / \Omega\right)
$$

where $\Omega \equiv W_{q} q / W$. Factoring out the positive common term $W_{q} / W$ yields

$$
\Phi=-(1-\alpha) t^{*}+\frac{S_{w}^{*} w}{q^{*}}\left(1+\Omega^{*}+\Omega_{q}^{*} q / \Omega\right) .
$$

The right hand side of (17) simplifies further using the properties of the surplus function $S^{*}$ and the first order condition. First, note that

$$
S^{*} / q^{*}=S_{q^{*}}^{*}+(1-\alpha) t^{*}
$$

The first order condition substituted on the right hand side above implies $S^{*} / q^{*}=-S_{w}^{*} W_{q^{*}}+(1-\alpha) t^{*}$. Then $-(1-\alpha) t^{*}=-S^{*} / q^{*}-S_{w}^{*} W_{q^{*}}$. Substituting into (17) and simplifying,

$$
\Phi=-\frac{S^{*}}{q^{*}}+\frac{S_{w}^{*} w}{q^{*}}+\frac{S_{w}^{*} w}{q^{*}} \Omega_{q}^{*} q / \Omega .
$$

Utilizing the properties of $S^{*}$, the first two terms simplify, yielding

$$
\Phi=c-M^{*} b^{*}+\frac{S_{w}^{*} w}{q^{*}} \Omega_{q}^{*} q / \Omega .
$$


Since $\Phi$ signs $R_{q}^{*}$, (18) allows a complete characterization of possible equilibrium configurations. $\Omega_{q}^{*}>0$, which will be proved below. Enforcement is weak or strong as $M^{*} b^{*}-c<(1-\alpha)\left(b^{*}-c\right)$ or $M^{*} b^{*}-c>(1-\alpha)\left(b^{*}-c\right)$ (implying $S_{w}^{*}>0$ or $S_{w}^{*}<0$ ). Therefore $R_{q}^{*}>0$ for $M^{*} b^{*}-c<0$ while $R_{q}^{*}<0$ for $M^{*} b^{*}-c>(1-\alpha)\left(b^{*}-c\right)$. For $0<M^{*} b^{*}-c<(1-\alpha)\left(b^{*}-c\right)$ it is possible that despite $S_{w}^{*}>0, R_{q}^{*}<0$. Analogous procedures yield the analogous conditions that sign $R_{q^{*}}$.

It remains to prove that $\Omega_{q}^{*} q / \Omega>0$. This follows from

$$
W\left(q, q^{*}\right)=\frac{q(1-M)+q^{*}\left(1-M^{*}\right)}{N-k q^{1 / \alpha}-k^{*}\left(q^{*}\right)^{1 / \alpha}+q / \theta+q^{*} / \theta^{*}}
$$

hence

$$
\Omega=\frac{q(1-M)}{q(1-M)+q^{*}\left(1-M^{*}\right)}+\frac{k q^{1 / \alpha} / \alpha-q / \theta}{N-k q^{1 / \alpha}-k^{*}\left(q^{*}\right)^{1 / \alpha}+q / \theta+q^{*} / \theta^{*}}
$$

which simplifies to

$$
\Omega=\frac{q(1-M)}{q(1-M)+q^{*}\left(1-M^{*}\right)}\left\{1+\frac{t / \alpha-(\pi-M)}{1-M}\right\}
$$

and similarly

$$
\Omega^{*}=\frac{q^{*}(1-M)}{q(1-M)+q^{*}\left(1-M^{*}\right)}\left\{1+\frac{t^{*} / \alpha-\left(\pi^{*}-M^{*}\right)}{1-M^{*}}\right\} .
$$

Finally,

$$
\frac{\Omega_{q}^{*} q}{\Omega}=\frac{q^{*}\left(1-M^{*}\right)}{q(1-M)+q^{*}\left(1-M^{*}\right)} \frac{-1+\frac{[t / \alpha-(\pi-M)]\left[t^{*} / \alpha-\left(\pi^{*}-M^{*}\right)\right]}{(1-M)\left(1-M^{*}\right)}}{1+\frac{t / \alpha-(\pi-M)}{1-M}} .
$$

Note that $\Omega>0$ implies $1+t / \alpha-\pi>0 \Rightarrow t / \alpha>\pi-1$. Replacing $t / \alpha$ with $\pi-1$ and $t^{*} / \alpha$ with $\pi^{*}-1$ lowers the numerator of the right hand side of (19), hence $\Omega_{q}^{*} q / \Omega>0$.

\section{Appendix 2: General Equilibrium}

\subsection{General Equilibrium}

All qualitative implications about commercial policy continue to hold in a simple general equilibrium model that embeds the partial equilibrium model 
of the text. The general equilibrium model resembles others in the trade literature built with the same purpose in mind. Terms of trade effects are shut down for simplicity because they present familiar elements for commercial policy analysis. ${ }^{29}$

Each country produces a numeraire good and an export good consumed only by foreigners. Numeraire production is given by an endowment in each country. The export good of the home country has unit labor requirement equal to $a$, so the cost of goods supplied by the home country to the foreign country is given by $c^{*}=a w$. Similarly the cost of goods supplied by the foreign country to the home country is given by $c=a^{*} w$. Unlike most trade models, labor is internationally mobile, so the wage rate is internationally equalized. Merchant capital, in contrast, is country-specific just as it was in the preceding sections. This leads to diminishing returns in the trade activity carried on by each set of merchants. The numeraire good is costlessly tradable ${ }^{30}$ but the non-numeraire goods require trade services. The direction of trade in the numeraire good is an inessential detail residually dependent on the details of the general equilibrium model that determine the volume of trade in the non-numeraire goods.

The predators prey on the non-numeraire good trade of each country, earning an expected return equal to the wage they could earn in productive activity, production of the export goods or in trade services. The stolen (or extorted) goods in expected amounts $q(1-\pi)$ and $q^{*}\left(1-\pi^{*}\right)$ are resold in the retail markets with the legitimate goods, but incur a fixed iceberg trade cost in doing so. Thus $b q(1-\pi)$ worth of non-numeraire goods nets the predators on home imports $(b / T) q(1-\pi)$ where $T \geq 1$. In the partial equilibrium model, the trade costs were set equal to $b$ so that the thieves' market price was equal to one. Here in contrast the thieves' market is integrated with the legitimate market as a simple way to close the general equilibrium model. For simplicity, $T=1=T^{*}$. 31

The predators come from the common labor pool and are all identical in

\footnotetext{
${ }^{29}$ Allowing for terms of trade effects can sometimes enable trade in a world that otherwise would be autarkic. Anderson and Marcouiller (2005) provide a model where terms of trade improvement raises the real wage of the poorer country, that supplies all the predators, by enough to reduce the lure of predation sufficiently to enable trade. The result suggests subsidizing trade to improve security, an argument that resembles those above.

${ }^{30}$ This simplification is inessential so long as trade costs are exogenous.

${ }^{31}$ It may be useful in future work to consider the use of $T$ as a policy instrument by the government, but for present purposes this is a distraction.
} 
their productivity in the various types of production and predation. They have tastes that differ, however, depending on their origin, so some of them spend their income in the home country, buying the home numeraire good and the foreign export good while the remainder of the predators spend their income in the foreign country buying the foreign numeraire good and the home export good. This setup closes the general equilibrium model in the simplest way that is consistent with the underlying deep cause of trade: taste differences.

Tastes are modeled with quasi-linear utility, linear in the numeraire good and a strictly concave function $f(z)=z^{\eta}, 0<\eta<1$ of the non-numeraire good in the home country and $f^{*}\left(z^{*}\right)=\left(z^{*}\right)^{\eta^{*}}$ in the foreign country. Under these assumptions, denoting the price of the numeraire good as $p$, the home buyer's willingness to pay for the non-numeraire good $b$ is given by $b=$ $p \eta z^{\eta-1}$. The foreign buyer's willingness to pay for the non-numeraire good (exported from the home country) is given by $z^{*}=p \eta^{*}\left(q^{*}\right)^{\eta^{*}-1}$. It is useful for future purposes below to note that expenditure on the non-numeraire good in terms of the numeraire is given by $b z / p=\eta f(z)$ and similarly for the foreign country. The individual demand $\mathrm{z}$ is scaled up by the number of agents with home tastes, $N$, to form the aggregate home demand for the non-numeraire good $q=N z$. Similarly, $q^{*}=N^{*} z^{*}$. (Thus each merchant owns one unit of labor, with the merchant group forming a fraction of $N, N^{*}$.) Demand for the numeraire good is given by $I / p-b q / p$ where $I$ is aggregate income, equal to $N w+S$ for the home country and $N^{*} w+S^{*}$ for the foreign country. This income aggregate includes the income received by all agents with national (home and foreign respectively) tastes, whether merchants or workers in the trade services, export production or predatory activities.

The merchants' exercise of monopoly power now includes their ability to exploit variation in the willingness to pay of consumers of the non-numeraire good. Marginal revenue is given by $N \pi p f^{\prime}\left(1+z f^{\prime \prime} / f^{\prime}\right)=N \pi \eta p f^{\prime}(q / N)$ in the home country. Integrating to form the merchants' (producers') surplus yields

$$
S(q, w ; p)=N \eta p(q / N)^{\eta}(M+w / \theta)-w a^{*} q-\alpha w k q^{1 / \alpha} .
$$

A similar expression describes the foreign surplus $S^{*}$. The merchant guild understands the dependence of $w$ on its choice of trade $q$ as previously, but it takes the numeraire price $p$ as given.

The labor market clears with global supply equal to global demand. The demand for labor includes that in trade services, $k q^{1 / \alpha}$, exports $a q^{*}$, and 
similarly for the foreign country. This implies

$$
N+N^{*}=a^{*} q+a q^{*}+k q^{1 / \alpha}+k^{*}\left(q^{*}\right)^{1 / \alpha^{*}}+(1-\pi) b q / w+\left(1-\pi^{*}\right) b^{*} q^{*} / w .
$$

The labor market clearance condition can be solved for the wage as a function of $\left(q, q^{*}, p\right)$ :

$$
W\left(q, q^{*}, p\right)=p \frac{(1-M) D+\left(1-M^{*}\right) D^{*}}{N+N^{*}+p D / \theta+p D^{*} / \theta^{*}-a q^{*}-a^{*} q-k q^{1 / \alpha}-k^{*}\left(q^{*}\right)^{1 / \alpha^{*}}},
$$

where $D=N \eta(q / N)^{\eta}$ and $D^{*}=N^{*} \eta^{*}\left(q^{*} / N^{*}\right)^{\eta^{*}}$.

The numeraire goods market clears with the world endowment equal to world demand. Using the expressions for merchants' surplus, the numeraire market clearance condition can be solved for the price as a function of $\left(q, q^{*}, w\right)$ :

$$
P\left(q, q^{*}, w\right)=w \frac{N+N^{*}-a q^{*}-a^{*} q-\alpha k q^{1 / \alpha}-\alpha^{*} k^{*}\left(q^{*}\right)^{1 / \alpha^{*}}}{y+y^{*}+D(1-M-w / \theta)+D^{*}\left(1-M^{*}-w / \theta^{*}\right)} .
$$

The simultaneous solution of $w=W\left(q, q^{*}, p\right)$ and $p=P\left(q, q^{*}, w\right)$ yields the reduced form solution $w=\tilde{W}\left(q, q^{*}\right)$ and $p=\tilde{P}\left(q, q^{*}\right)$. Assuming the stability condition $W_{p} P_{w}<1$ is met, both $w$ and $p$ are increasing in both $q$ and $q^{*}$.

With this general equilibrium machinery working in the background, the choice of $q, q^{*}$ by the merchant guilds proceeds as in the partial equilibrium setting. The conditions for the weak or strong enforcement regimes change, as explained in the Appendix, but the qualitative implications remain the same. There is a slight tension because the general equilibrium derivative $\tilde{W}_{q}$ incorporates the endogenous determination of $p$ while the merchant guild is assumed to take $p$ as given. The merchant guild may instead use $W_{q}$ in setting its quantity policy. This difference is, however, an inessential detail.

When equilibrium is secure, the labor market clearance condition above implies that the wage is no longer a function of $q, q^{*}$ directly. The model solves for the relative prices $p / w, b / w, b^{*} / w$ and the quantities $q, q^{*}$. The monopolists' power reduces to the standard power over the buyers' willingness to pay, taking the numeraire good's relative price in terms of labor as given. Demands for the non-numeraire good being independent across markets, strategic independence characterizes the interaction of merchant guilds and there is no role for strategic trade policy. 


\subsection{Comparative Statics of Equilibrium}

\subsubsection{Competitive Trade}

Competitive trade volume is determined by $S_{q}=0$. Then since $S_{q c}=$ $-1, d q / d c=1 / S_{q q}$. Differentiating with respect to $M$ yields $d^{2} q / d c d M=$ $-S_{q q}^{-2}\left[S_{q q M}+S_{q q q} d q / d M\right]$. Evaluating $S_{q q}$ shows that its dependence on $M$ comes through its dependence on $w$. Noting that $W_{M}=-W /(1-M)$ and hence $W_{q M}=-W_{q} /(1-M), S_{q q M}<0$. Moreover, $d q / d M>0$ and $S_{q q q}<0$ ordinarily and necessarily so if $S_{w} W_{q q}<0$. Then $d q / d c$ is ordinarily increasing algebraically, becoming less responsive in absolute value, the greater is $M$.

\subsubsection{Monopoly Trade}

A guild that controls trade volume chooses an interior volume where:

$$
-S_{q} / S_{w}=W_{q}
$$

Figures 2 and 3 illustrate. Characterizing the equilibrium depends on the shape of the iso-surplus contours. This is determined by two limiting values of the derivatives of the surplus function. $S_{w}=0 \Rightarrow q^{w}=(b / \theta k \alpha)^{\alpha /(1-\alpha)}$. All iso-surplus contours asymptotically approach $q^{w}$. Evaluating $S_{q}=0$ at the secure equilibrium wage $w=\theta(1-M)$,

$$
S_{q}[q, \theta(1-M), M]=0 \Rightarrow q^{0}=\left(\frac{b-c}{\theta k(1-M)}\right)^{\alpha /(1-\alpha)} .
$$

The case $q^{0}>q^{w}$ implies that the interior equilibrium is associated with $S_{q}>0$. Manipulating the expressions for $q^{w}$ and $q^{0}, S_{q}>0$ if and only if $M>1-\alpha+\alpha c / b$ while $S_{q}<0$ if and only if $M<1-\alpha+\alpha c / b$. These are the strong enforcement and weak enforcement cases respectively.

It is straightforward to show that the curvature of the surplus function in the two cases is as depicted in Figures 2 and 3.

Interior equilibrium requires that the second order condition is met, and that positive profits are earned. It is possible that autarky is the only stable equilibrium or that secure trade is the only stable equilibrium. See Anderson and Bandiera for more discussion of existence in a closely related model in which all qualitative issues are the same. (In that model, a monopoly enforcer 
provides $M$ and maximizes profits by pricing enforcement sold to competitive traders.)

The effect of a change in $c$ is shown graphically in the two figures. For the monopoly case, the comparative static derivative is given by $d q / d c=$ $1 /\left[S_{q q}+S_{w q} W_{q}+S_{w} W_{q q}\right]$.

As with the competitive case, the effect of $M$ on the marginal response arises through its effect on the wage along with the effect of $M$ on $q$. It can be shown that the denominator is decreasing in $M$ provided that $S_{w} W_{q q}>0$ and additionally if $S_{w} W_{q q q}<0$. These are oversufficient conditions. Thus trade is ordinarily less responsive to reductions in $c$ the larger is $M$.

\subsubsection{Monopoly in General Equilibrium}

The surplus contours of the monopolist in $(w, q)$ space are shaped qualitatively like those of the partial equilibrium case. Evaluating the limiting values of the general equilibrium surplus function (20) at $S_{w}=0$ and $S_{q}(q, \theta(1-M))=0$ yields

$$
q^{w}=\left(\frac{\omega b-a^{*}}{\alpha k}\right)^{\alpha /(1-\alpha)}
$$

and

$$
q^{0}=\left(\frac{\omega b-\theta(1-M) a^{*}}{\theta(1-M) k}\right)^{\alpha /(1-\alpha)} .
$$

This implies that the critical condition is

$$
M>(<) 1-\alpha+\alpha \frac{a^{*}}{\omega b /(1-\alpha) \theta-a^{*}} .
$$

Compared to the partial equilibrium condition characterizing weak and strong enforcement regimes, $c / b$ is replaced by $c /[\gamma b-c]$ where $\gamma=\omega(\pi-M) b /(1-$ $\alpha), c=a^{*} w, \pi-M=w / \theta$. Unlike the partial equilibrium condition, the variable $b$ on the right hand side is a (decreasing) function of $q$, so the condition holds under unspecified deeper relationships among the parameters that determine equilibrium. Otherwise it has qualitatively similar implications. 


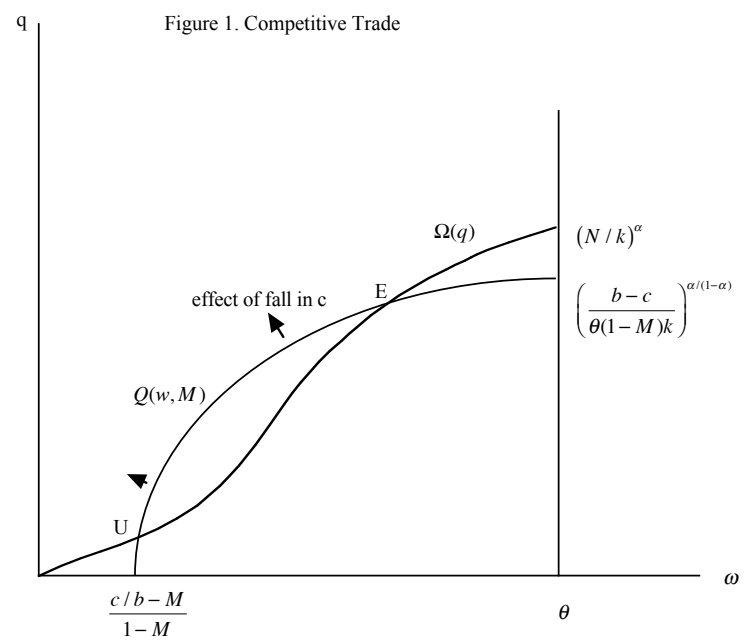




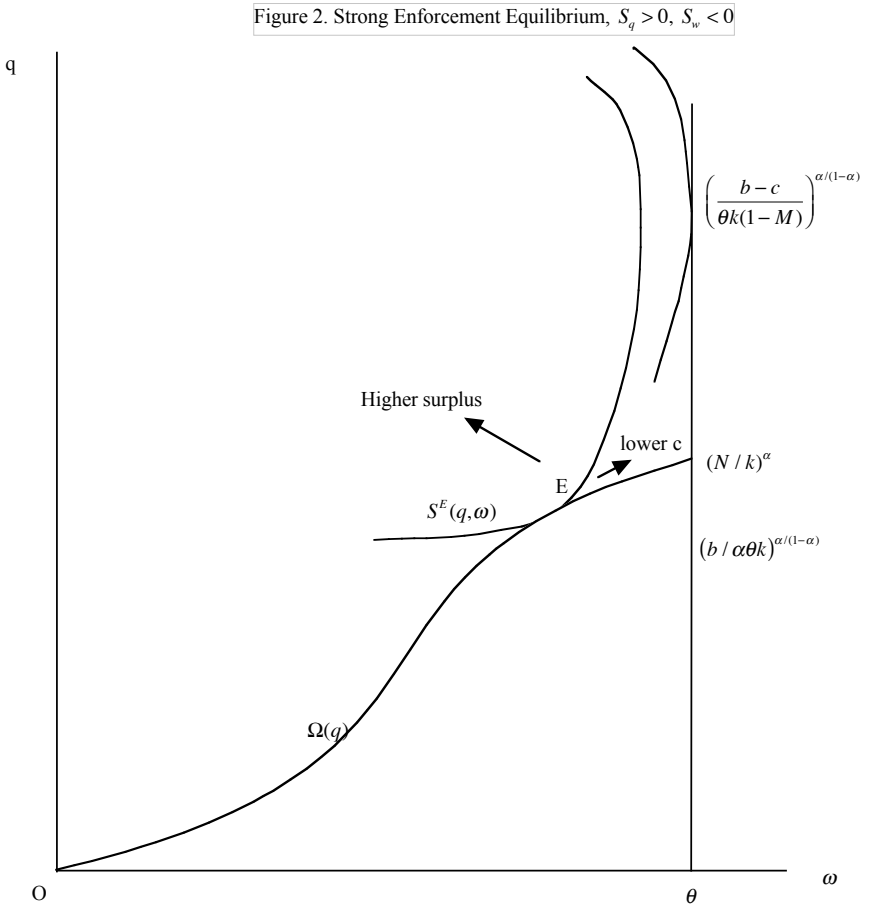




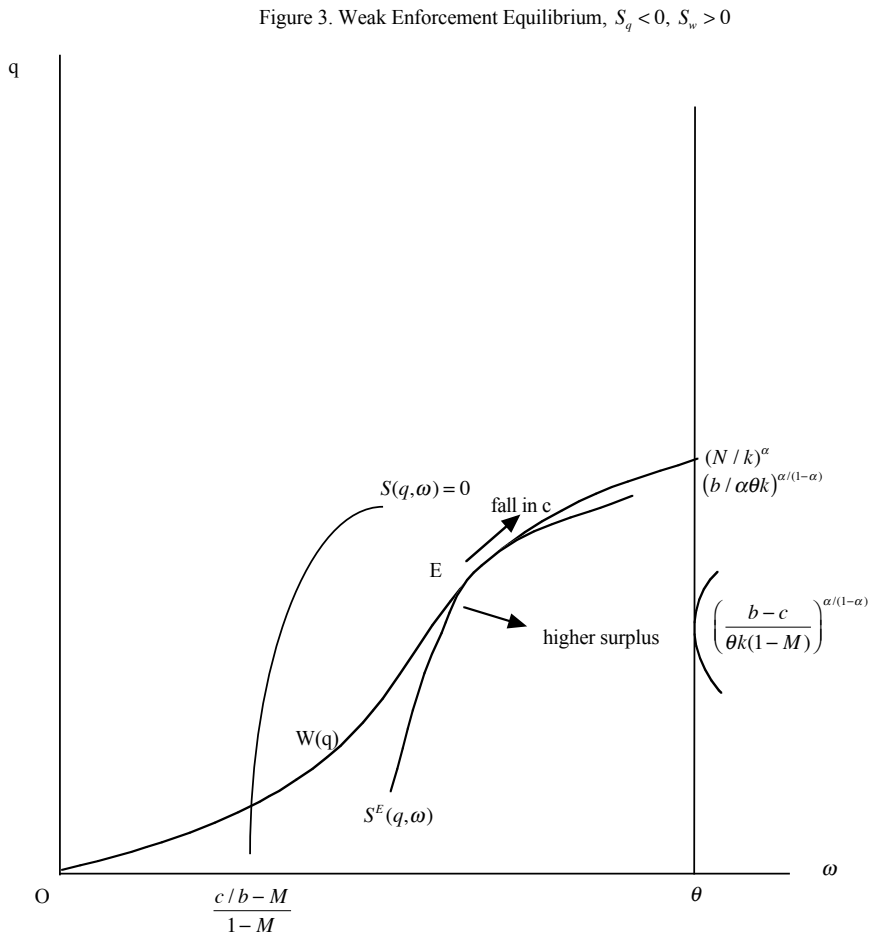




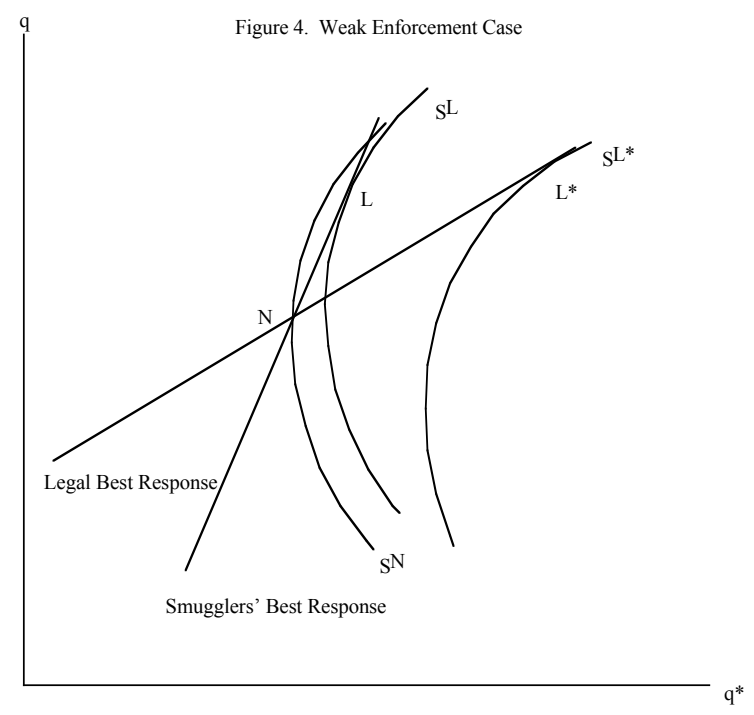

38 


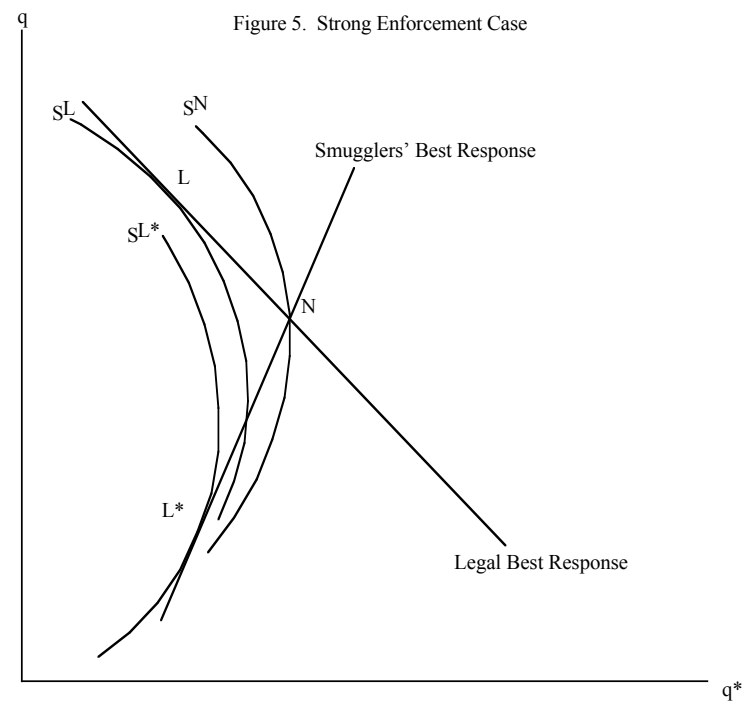


Table 2. Composite Security Scores

\begin{tabular}{lclcll}
\hline IMPORTER & Score & IMPORTER & Score & IMPORTER & Score \\
\hline Russia & -2.614 & Italy & -0.362 & France & 0.689 \\
Ukraine & -2.377 & Indonesia & -0.284 & Australia & 0.704 \\
Venezuela & -2.218 & India & -0.264 & Sweden & 0.779 \\
Colombia & -2.098 & Zimbabwe & -0.240 & Austria & 0.807 \\
Greece & -1.195 & Peru & -0.235 & Denmark & 0.857 \\
Poland & -0.858 & Korea & -0.217 & Ireland & 0.864 \\
Thailand & -0.796 & China & -0.184 & Germany & 0.931 \\
Jordan & -0.794 & Belgium-Luxembourg & 0.055 & New Zealand & 0.997 \\
Hungary & -0.791 & Egypt & 0.227 & United Kingdom & 1.034 \\
Mexico & -0.749 & Spain & 0.382 & Netherlands & 1.036 \\
South Africa & -0.602 & Portugal & 0.391 & Canada & 1.050 \\
Argentina & -0.579 & Iceland & 0.451 & China: Hong Kong & 1.134 \\
Turkey & -0.539 & Malaysia & 0.499 & Norway & 1.142 \\
Slovak Republic & -0.524 & Japan & 0.562 & Switzerland & 1.159 \\
Brazil & -0.521 & United States & 0.651 & Finland & 1.173 \\
Czech Republic & -0.452 & Chile & 0.680 & Singapore & 1.241 \\
\hline
\end{tabular}

